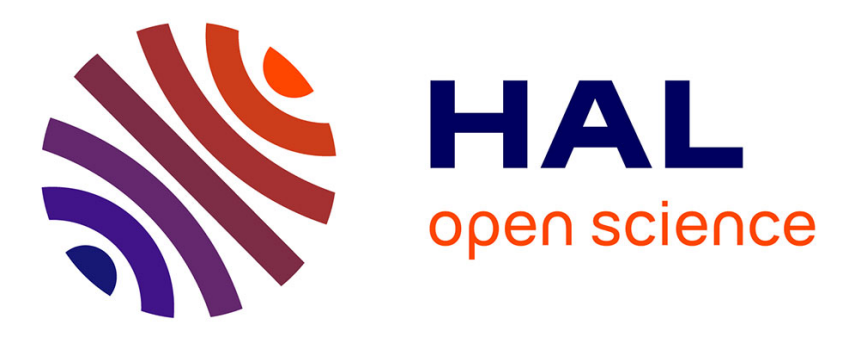

\title{
Distal enlargement of the optic nerve sheath in the hyperacute stage of intracerebral hemorrhage
}

\author{
David Školoudík, Roman Herzig, Táòa Fadrná, Michal Bar, Pavel Hradílek, \\ Martin Roubec, Monika Jelínková, Daniel Šaòák, Michal Král, Jana \\ Chmelová, et al.
}

\section{To cite this version:}

David Školoudík, Roman Herzig, Táòa Fadrná, Michal Bar, Pavel Hradílek, et al.. Distal enlargement of the optic nerve sheath in the hyperacute stage of intracerebral hemorrhage. British Journal of Ophthalmology, 2010, 95 (2), pp.217. 10.1136/bjo.2009.172890 . hal-00561325

\section{HAL Id: hal-00561325 https://hal.science/hal-00561325}

Submitted on 1 Feb 2011

HAL is a multi-disciplinary open access archive for the deposit and dissemination of scientific research documents, whether they are published or not. The documents may come from teaching and research institutions in France or abroad, or from public or private research centers.
L'archive ouverte pluridisciplinaire HAL, est destinée au dépôt et à la diffusion de documents scientifiques de niveau recherche, publiés ou non, émanant des établissements d'enseignement et de recherche français ou étrangers, des laboratoires publics ou privés. 


\section{Title page}

Distal enlargement of the optic nerve sheath in the hyperacute stage of intracerebral hemorrhage

David Školoudík, MD, $\mathrm{PhD}^{1,2}$, Roman Herzig, MD, PhD, FESO ${ }^{2}$, Táňa Fadrná ${ }^{\prime}$, Michal Bar, MD, $\mathrm{PhD}^{l}$, Pavel Hradílek, $\mathrm{MD}, \mathrm{PhD}^{l}$, Martin Roubec, $\mathrm{MD}^{l}$, Monika Jelínková, $\mathrm{MD}^{l}$, Daniel Šaňák, MD, $\mathrm{PhD}^{2}$, Michal Král, $\mathrm{MD}^{2}$, Jana Chmelová, MD, $\mathrm{PhD}^{3}$, Miroslav Heřman, $\mathrm{MD}$, $\mathrm{PhD}^{4}$, Kateřina Langová, $\mathrm{MA}^{5}$, Petr Kaňovský, $\mathrm{MD}, \mathrm{PhD}^{2}$

${ }^{1}$ Department of Neurology and ${ }^{3}$ Radiology, University Hospital and University of Ostrava, Ostrava, Czech Republic

${ }^{2}$ Department of Neurology and ${ }^{4}$ Radiology, Faculty of Medicine and Dentistry, Palacký University and University Hospital, Olomouc, Czech Republic

${ }^{5}$ Institute of Medicine Biophysics, Faculty of Medicine and Dentistry, Palacký University, Olomouc, Czech Republic

\section{Address for correspondence:}

Assoc. Prof. David Školoudík, MD, PhD

Department of Neurology

University Hospital Ostrava

Tr. 17. listopadu 1790

CZ-708 52 Ostrava

Czech Republic

Telephone: +420604840104

Fax: +420597375664

e-mail: skoloudik@hotmail.com 
Number of tables: [5]

Table 1. Inclusion and exclusion criteria

Table 2. Demographic and clinical data in study subgroups

Table 3. Diameters and relative enlargement of the optic nerve sheath in study subgroups

Table 4. Differences of optic nerve sheath diameters between the side of intracerebral hemorrhage and contralateral side in particular patients.

Table 5. Sensitivity, specificity, positive and negative predictive values, accuracy and Cohen’s $\kappa$ correlation coefficient for different sonographic cut-point values of optic nerve sheath enlargement to predict intracerebral hemorrhage volume $>2.5 \mathrm{~cm}^{3}$ and midline shift $\geq$ $2.0 \mathrm{~mm}$ in patients with acute intracerebral hemorrhage

Number of Figures: [2]

Figure 1: Normal finding of the optic nerve without enlargement of the optic nerve sheath diameter

Figure 2: Enlargement of the optic nerve sheath diameter in patient with acute intracerebral hemorrhage

Abstracts words: [199]

Manuscripts words: [2419]

Key words: intracerebral hemorrhage, intracranial pressure, optic nerve, ultrasound 
Licence for Publication: The Corresponding Author has the right to grant on behalf of all authors and does grant on behalf of all authors, an exclusive licence on a worldwide basis to the BMJ Publishing Group Ltd to permit this article (if accepted) to be published in BJO and any other BMJPGL products and sublicences such use and exploit all subsidiary rights, as set out in our licence (http://group.bmj.com/products/journals/instructions-for-authors/licenceforms).

Competing Interest: None declared.

\section{Funding sources:}

The study was partially supported by the grant projects of the Ministry of Education, Czech Republic, number MSM6198959216. There are no conflicts of interest associated with this manuscript, financial or otherwise. 


\section{Abstract}

Background: The optic nerve sheath diameter (ONSD) enlargement is detectable in patients with increased intracranial pressure. The aim was to detect an enlargement of the ONSD using optic nerve sonography (ONS) in patients with acute intracerebral hemorrhage (ICH) within 6 hours from symptoms onset.

Methods: Thirty-one acute ICH patients, 15 age-matched acute ischemic stroke patients and 16 age-matched healthy volunteers were consecutively enrolled in the prospective bi-center observational study. All acute stroke patients underwent brain computed tomography (CT), ONS and transcranial color-coded duplex sonography (TCCS) at admission within 6 hours after stroke onset. The ONSD in both $3.0 \mathrm{~mm}$ and $12.0 \mathrm{~mm}$ behind the globe using ONS, age, gender, hemorrhage volume and midline shift measured by CT, blood flow velocities in both middle cerebral arteries using TCCS were recorded and statistically evaluated.

Results: In acute ICH patients, a significant enlargement of ONSD was detected $(\mathrm{p}<0.0083)$. The best cut-off point to predict ICH volume $>2.5 \mathrm{~cm}^{3}$ was the relative ONSD enlargement of $>0.66 \mathrm{~mm}(>21 \%)$, with $90.3 \%$ accuracy and kappa coefficient 0.760 (95\% CI $0.509-$ $1.000)$.

Conclusion: Sonographicaly measured enlargement of the ONSD may be detectable already in hyperacute stage of increased intracranial pressure.

Key words: intracerebral hemorrhage, intracranial pressure, optic nerve, ultrasound 


\section{Introduction}

Several studies have demonstrated the optic nerve sheath diameter (ONSD) is enlarged in patients with increased intracranial pressure (ICP). ${ }^{1-19}$ Both optic nerve sonography ${ }^{1-18}$ and magnetic resonance ${ }^{19}$ can be used to measure ONSD. Optic nerve sonography is an inexpensive and rapid bedside procedure with virtually no risk to patients. This technique can be used as a non-invasive method to detect increased ICP before a decision to use invasive neurosurgical monitoring, to select patients who will benefit, and to avoid complications associated with these procedures when used in non-selected patients. ${ }^{4,18}$ Optic nerve sonography is a simple technique to learn. Foster et $\mathrm{al}^{20}$ demonstrated only minor interobserver variability of ONSD measurements between emergency department physicians. Previous studies demonstrated a strong correlation between sonographic ONSD measurements, non-invasive or invasive ICP measurements, and brain computed-tomography (CT) findings in patients with head injury. ${ }^{16-18}$

Previous sonographic studies reported ONSD enlargement both in children ${ }^{1,7-12}$ and in adults $^{2-5,13-18}$ with increased ICP of different etiologies (e.g. hydrocephalus, head trauma, intracranial hemorrhage, malignant stroke, brain edema, meningitis, metabolic disorders, diabetic ketoacidosis). These studies established that the normal ONSD is up to 4.0 $\mathrm{mm}$ in children younger than one year, up to $4.5 \mathrm{~mm}$ between the ages of one and eighteen years, and up to $5.0 \mathrm{~mm}$ in adults (>18 years). ${ }^{9,2,12,21}$

ONSD enlargement is an early sign of increased ICP that is detectable in head injury patients within 48 hours of injury. ${ }^{16-18}$ However, it is possible that ONSD enlargement could be detectable in the first hours after the increase in ICP. The present study therefore had two primary aims. The first was to investigate whether ONSD enlargement could be detected in patients with acute intracerebral hemorrhage $(\mathrm{ICH})$ within 6 hours of symptom onset and to compare the results with acute ischemic stroke patients and healthy controls. The second aim 
was to compare the extent of distal enlargement of the optic nerve sheath to hemorrhage

volume and the midline shift measured using brain $\mathrm{CT}$, and to the resistance indices in both the middle cerebral arteries (MCAs) measured using transcranial color-coded duplex sonography (TCCS). 


\section{Material and Methods}

\section{Patients}

Thirty-one acute hemorrhagic-stroke patients, 15 age-matched acute ischemic stroke patients and 16 age-matched healthy volunteers were consecutively enrolled over a period of 12 months in the prospective bi-center observational study. All acute stroke patients underwent

physical and neurological examination, brain $\mathrm{CT}$ and neurosonological examination including cervical artery duplex sonography, optic nerve sonography and transcranial color-coded duplex sonography (TCCS) at admission within 6 hours after stroke onset. Inclusion and exclusion criteria are listed in Table 1.

The following demographic and clinical data were recorded and evaluated: age, gender, hemorrhage volume and midline shift as measured by CT, peak systolic velocities, end-diastolic velocities and resistance indices measured in both the ipsilateral and contralateral MCAs using TCCS, optic nerve sonography data, risk factors (arterial hypertension, diabetes, hyperlipidemia, smoking), extracranial arterial findings detected by extracranial duplex sonography (EDS), and score on the National Institute of Health Stroke Scale (NIHSS) at admission.

\section{Optic nerve sonography}

Optic nerve sonography was performed at admission and within 6 hours of stroke onset by an experienced sonographer blinded to brain CT findings. All patients were examined in the supine position. Both eyes were scanned using a linear probe 5-12 MHz (L12-5, Philips HD 11, Saronno, Italy) at the University Hospital Olomouc and a linear probe 5-10 MHz (L10-5, Philips HDI 5000, Bothel USA) at the University Hospital Ostrava. The linear probe was placed lightly over the closed upper eyelid of the patient. The structures of the eye were visualized to align the optic nerve directly opposite the probe, and with the width of the optic 
nerve sheath diameter perpendicular to the vertical axis of the scanning plane. ${ }^{18}$ The ONSD was measured at depths of both $3.0 \mathrm{~mm}(\mathrm{~A})$ and $12.0 \mathrm{~mm}(\mathrm{~B})$ behind the globe (papilla of the eye) on both sides (Figures 1,2). Due to safety reasons, the lowest possible ultrasound intensity and the shortest possible insonation time were used to avoid any damage of eye structures. $^{22}$

Three measures of ONSD enlargement were employed. (1) The absolute value of ONSD $3.0 \mathrm{~mm}$ behind the globe. An ONSD >5.0 $\mathrm{mm}$ was considered to be abnormal/pathological. ${ }^{2,12,18,21}$ (2) The relative ratio (RR) of the ONSDs at depths of $3.0 \mathrm{~mm}$ (a) and $12.0 \mathrm{~mm}$ (b) behind the globe $(\mathrm{RR}=\mathrm{a} / \mathrm{b} \times 100$; i.e. the relative enlargement ratio in

$\%)$. Two cut-off points were specified - the $95^{\text {th }}$ percentile of the ONSD relative enlargement ratio in healthy volunteers, and ONSD relative enlargement ratio three times over the $95^{\text {th }}$ percentile of in healthy volunteers. (3) The relative difference (RD) between the ONSD at depths of $3.0 \mathrm{~mm}$ (a) and $12.0 \mathrm{~mm}$ (b) behind the globe $(\mathrm{RD}=\mathrm{a}-\mathrm{b}$; i.e. the relative enlargement in mm). Two cut-off points were specified - the $95^{\text {th }}$ percentile of ONSD relative enlargement in healthy volunteers, and ONSD relative enlargement three times over the $95^{\text {th }}$ percentile of in healthy volunteers.

The presence of papilledema was assessed in all patients using the B-mode.

\section{Brain CT examination}

Brain CT scanning was performed in all patients at admission within 6 hours after symptom onset. The results were evaluated by an on-site radiologist blinded to the optic nerve sonography results. The ICH volume was calculated from the axial section thicknesses at 2 and $0.75 \mathrm{~mm}$ by a plane geometry method. The midline shift was measured from the section at the level of the third ventricle. 


\section{Statistical analysis}

Kolmogorov-Smirnov and the Shapiro-Wilk tests were used for testing the correspondence of calculated parameters to a normal distribution. All parameters not fitting to a normal distribution are presented as mean, median and interquartile ranges (IQR); the non-parametric Kruskal-Wallis test was used to compare the 3 sub-groups. Multiple comparisons employed a non-parametric two-sided Mann-Whitney U-test, while the Wilcoxon signed ranks test was used for pairwise comparison between subgroups. Statistical analyses were performed using SPSS 14.0 software (SPSS Inc., Chicago, IL, USA). Bonferonni correction was applied; $p<0.05$ was considered to indicate statistical significance.

Spearman rank correlation was used to assess correlations between relative, resp. absolute ONSD enlargement, and intracerebral hemorrhage (ICH) volume, midline shift and resistance indices in both MCAs.

Correlation tables, with sensitivity, specificity, predictive values, Cohen's $\mathrm{K}$ and AC1 coefficient were used to compare separately the results of both absolute and relative ONSD measurements, intracerebral hemorrhage (ICH) and midline shift data, against both the $95^{\text {th }}$ percentiles of ONSD relative enlargement and ONSD relative enlargement three times over $95^{\text {th }}$ percentiles of ONSD in healthy volunteers.

\section{Ethics}

The study was conducted in accordance with the Helsinki Declaration of 1975 (as revised in 1983 and 2008), and was approved by the local ethical committees of both hospitals. Written informed consent was obtained from all subjects. 


\section{Results}

Thirty-one acute hemorrhagic stroke patients, 15 acute ischemic stroke patients and 16 healthy volunteers were enrolled in the prospective case-control study over a period of 12 months (January 2008 - December 2008). The characteristics of the subjects are presented in Table 2. The mean, median and interquartile ranges of ONSD at depths of 3.0 and $12.0 \mathrm{~mm}$ depths behind the globe are presented in the Table 3. In healthy volunteers, the $95^{\text {th }}$ percentiles of ONSD relative enlargement ratio and ONSD relative enlargement at depths of 3.0 and $12.0 \mathrm{~mm}$ were respectively $7 \%$ and $0.22 \mathrm{~mm}$. The $95^{\text {th }}$ percentiles of ONSD relative enlargement ratio and ONSD relative enlargement at depths of 3.0 and $12.0 \mathrm{~mm}$ in acute ischemic stroke patients were respectively $7 \%$ and $0.23 \mathrm{~mm}$; these values did not differ significantly from those in healthy volunteers $(p>0.05)$.

A significant enlargement of ONSD was seen in acute hemorrhagic stroke patients at a depth of $3.0 \mathrm{~mm}$ behind the globe $(p<0.0083)$ (Table 3). ONSD difference between the right and left side found in particular patients is presented in Table 4 . The average difference was $0.27 \pm 0.24 \mathrm{~mm}(p>0.05)$. Spearmann rank correlation coefficients between ONSD relative/absolute enlargement and $\mathrm{ICH}$ volume, midline shift, and resistive indices in both the ipsilateral and contralateral MCAs were 0.676/0.644, 0.720/0.686, 0.620/0.486 and $0.513 / 0.452$, resp. A relative enlargement of ONSD of $>0.66 \mathrm{~mm}$ or $>21 \%$ respectively was not detected in any patient with an ICH volume less than $2.5 \mathrm{~cm}^{3}$ but was found in $86 \%$ of patients with an ICH volume of $>2.5 \mathrm{~cm}^{3}$. Similarly, an ONSD exceeding $5.0 \mathrm{~mm}$ was not detected in any patient with ICH volume $<2.5 \mathrm{~cm}^{3}$ but, in contrast to the previous method of measurement, this was detected in only $71 \%$ patients with $\mathrm{ICH}$ volume $>2.5 \mathrm{~cm}^{3}$.

The sensitivity, specificity, negative and positive predictive values of the correlation of ONSD enlargement with an ICH volume of less than $2.5 \mathrm{~cm}^{3}$ and a midline shift of $\geq 2.0$ $\mathrm{mm}$ are presented in Table 5. The cut-off points predictive of an $\mathrm{ICH}$ volume $>2.5 \mathrm{~cm}^{3}$ were 
respectively a relative enlargement of $>0.66 \mathrm{~mm}$ and a relative enlargement ratio of $21 \%$

(ONSD relative enlargement three times over the $95^{\text {th }}$ percentile of the normal value), with an accuracy of $90.3 \%$ and a kappa coefficient 0.760 (95\% CI, $0.50-1.000)$.

Papilledema (as assessed by ultrasound) was not present in any patient. 


\section{Discussion}

The aim of this study was to assess ONSD enlargement at a hyperacute stage of increased ICP. Only acute hemorrhagic stroke patients were included in the study because the timing of the onset of symptoms and of ICP increase is well defined. Rapid ONSD enlargement was detected using optic-nerve sonography in acute hemorrhagic stroke patients with a hemorrhage volume of $>2.5 \mathrm{~cm}^{3}$. In the hyperacute stage of intracranial hypertension, measurement of the relative enlargement of the ONSD appeared to be more sensitive indicator than the absolute ONSD value.

Although both an absolute value of ONSD in excess of $5.0 \mathrm{~mm}$ and ONSD relative enlargement of $0.66 \mathrm{~mm}$ (or $21 \%$ ) were not detected in any acute ischemic stroke patients or healthy volunteers, the first one was detected in only $71 \%$ of acute ICH patients but the latter one was detected in $86 \%$ acute ICH patients. Relative ONSD enlargement thus seems to be more sensitive in patients with only slightly increased ICP because it was detectable in patients with an ICH volume exceeding $2.5 \mathrm{~cm}^{3}$ whereas an ONSD of over $5 \mathrm{~mm}$ was only detected in patients with an ICH volume exceeding $8.0 \mathrm{~cm}^{3}$.

The mean ONSD, 3.37-4.42 mm, measured $3.0 \mathrm{~mm}$ behind the globe in the control groups accords with the study published by Körber et al. ${ }^{8}$ The mean ONSD at $12.0 \mathrm{~mm}$ behind the globe did not significantly differ between the three study subgroups. In healthy volunteers and acute ischemic stroke patients, ONSD did not significantly differ at either 3.0 or $12.0 \mathrm{~mm}$ behind the globe.

The optic nerve is a part of the central nervous system, and the intraorbital subarachnoidal space surrounding the optic nerve is subject to the same pressure changes as the intracranial compartment. ${ }^{4,6,7,21,23}$ In the case of an increase of ICP, the pressure also rises inside the optic nerve sheath. Because the intraorbital part of the subarachnoid space is distensible, it may inflate through the accumulation of cerebrospinal fluid, so leading to an 
enlargement of the ONSD. Following injections into the orbital perineural subarachnoid space in cadavers the observed enlargement of the ONSD was predominantly in the anterior portions. ${ }^{6,21,23}$ The results of the present study accord with these findings.

This and other work has established that there is wide inter-individual variability in measurements of ONSD. In the present study the range was from 2.6-4.4 mm, while other studies ${ }^{17,24}$ have reported a range of $2.2-4.9 \mathrm{~mm}$, and a range of 2.1-4.8 $\mathrm{mm}$ was recorded in untreated postmortem specimen. ${ }^{6}$ It therefore appears more useful to measure relative ONSD enlargement in patients in the hyperacute stage of increased ICP when enlargement affects only the distal part of the optic nerve sheath.

It is not known why some patients with increased ICP do not exhibit ONSD enlargement. In the present study, 3 patients with ICH volume $>8.0 \mathrm{~cm}^{3}$ had no enlargement of ONSD. In two of these patients there was cortical atrophy and no midline shift was present. Nevertheless, we have as yet no explanation for the normal ONSD recorded in a patient with an ICH volume of $13.4 \mathrm{~cm}^{3}$ and a $4 \mathrm{~mm}$ midline shift. It is possible that sonographic findings may give false-negative results in some patients, or that the optic nerve sheath is unable to enlarge in some individuals (for instance due to the different characteristics of the optic nerve sheath or differential communication between the orbital perineural subarachnoid space and the intracranial subarachnoid space). It is also possible that enlargement might merely be delayed in some patients. In such case, computer assisted cisternography, enabling to assess the cerebrospinal fluid (CSF) dynamics between the intracranial CSF spaces and the subarachnoid space of the optic nerve, could be of benefit as reported previously. ${ }^{25}$

Despite their clinical and technical limitations, transcranial Doppler or duplex sonography and optic nerve sonography are becoming increasingly popular as supplementary neuromonitoring tools in the intensive care unit (ICU). Both techniques are non-invasive and easily accessible, so facilitating rapid bedside evaluation of patients in intensive care. ${ }^{17}$ 
Changes in blood flow velocities and indices in the intracranial arteries are detectable at the very early stages of increased ICP,${ }^{26}$ we report that these early changes are accompanied by measurable enlargement of ONSD. Optic nerve sonography might therefore be useful for ICP monitoring in intensive care patients contra-indicated for invasive ICP monitoring. The method could also be applied in a diagnostic algorithm in ICU patients before a definitive decision is taken regarding intracranial catheter implantation for ICP monitoring.

Although optic nerve sonography is relatively simple to learn and ONSD measurements have only minor inter-observer variability, the method has technical limitations and, as with other sonographic methods, is operator-dependent. The lowest possible ultrasound intensity and the shortest possible insonation time should be used to avoid any tissue damage. This can be accomplished in the case the examination is performed by an experienced sonographer.

Two limitations of the present study should be mentioned. Fundoscopy was not performed in all patients and the presence of papilledema was assessed only by ultrasound. Also ICP measurements were not made in the study patients because appropriate recording is not possible at the hyperacute stage of stroke. Future research will include prospective study of a larger number of acute ICH patients combined with non-invasive or invasive ICP measurement and repeated ONSD measurements. Such a combined approach is likely to provide useful information regarding the dynamics of ONSD enlargement and the potential use of optic nerve sonography in ICU patients. 


\section{References}

1. Beare NA, Kampondeni S, Glover SJ, Molyneux E, Taylor TE, Harding SP, Molyneux ME. Detection of raised intracranial pressure by ultrasound measurement of optic nerve sheath diameter in African children. Trop Med Int Health 2008;13(11):1400-1404.

2. Blaivas M, Theodoro D, Sierzenski PR. Elevated intracranial pressure detected by bedside emergency ultrasonography of the optic nerve sheath. Acad Emerg Med 2003;10(4):376-381.

3. Gangemi M, Cennamo G, Maiuri F, D'Andrea F. Echographic measurement of the optic nerve in patients with intracranial hypertension. Neurochirurgia 1987;30(2):53-55.

4. Geeraerts T, Merceron S, Benhamou D, Vigué B, Duranteau J. Non-invasive assessment of intracranial pressure using ocular sonography in neurocritical care patients. Intensive Care Med 2008;34(11):2062-2067.

5. Girisgin AS, Kalkan E, Kocak S, Cander B, Gul M, Semiz M. The role of optic nerve ultrasonography in the diagnosis of elevated intracranial pressure. Emerg Med J 2007;24(4):251-254.

6. Hansen HC, Helmke K. The subarachnoid space surrounding the optic nerves. An ultrasound study of the optic nerve sheath. Surg Radiol Anat 1996;18(4):323-328.

7. Helmke K, Hansen HC. Fundamentals of transorbital sonographic evaluation of optic nerve sheath expansion under intracranial hypertension II. Patient study. Pediatr Radiol 1996;26(10):706-710.

8. Körber F, Scharf M, Moritz J, Dralle D, Alzen G. Sonography of the optical nerve experience in 483 children. Rofo 2005;177(2):229-235.

9. Le A, Hoehn ME, Smith ME, Spentzas T, Schlappy D, Pershad J. Bedside sonographic measurement of optic nerve sheath diameter as a predictor of increased intracranial pressure in children. Ann Emerg Med 2009;53(6):785-791. 
10. Malayeri AA, Bavarian S, Mehdizadeh M. Sonographic evaluation of optic nerve diameter in children with raised intracranial pressure. Ultrasound Med 2005;24(2):143147.

11. McAuley D, Paterson A, Sweeney L. Optic nerve sheath ultrasound in the assessment of paediatric hydrocephalus. Childs Nerv Syst 2009;25(1):87-90.

12. Newman WD, Hollman AS, Dutton GN, Carachi R. Measurement of optic nerve sheath diameter by ultrasound: a means of detecting acute raised intracranial pressure in hydrocephalus. Br J Ophthalmol 2002;86(10):1109-1113.

13. Kimberly HH, Shah S, Marill K, Noble V. Correlation of optic nerve sheath diameter with direct measurement of intracranial pressure. Acad Emerg Med 2008;15(2):201-204.

14. Moretti R, Pizzi B. Optic nerve ultrasound for detection of intracranial hypertension in intracranial hemorrhage patients: confirmation of previous findings in a different patient population. J Neurosurg Anesthesiol 2009;21(1):16-20.

15. Schwab S, Aschoff A, Spranger M, Albert F, Hacke W. The value of intracranial pressure monitoring in acute hemispheric stroke. Neurology 1996;47(2):393-398.

16. Karakitsos D, Soldatos T, Gouliamos A, Armaganidis A, Poularas J, Kalogeromitros A, Boletis J, Kostakis A, Karabinis A. Transorbital sonographic monitoring of optic nerve diameter in patients with severe brain injury. Transplant Proc 2006;38:3700-3706.

17. Soldatos T, Karakitsos D, Chatzimichail K, Papathanasiou M, Gouliamos A, Karabinis A. Optic nerve sonography in the diagnostic evaluation of adult brain injury. Crit Care 2008;12:R67.

18. Tayal VS, Neulander M, Norton HJ, Foster T, Saunders T, Blaivas M. Emergency department sonographic measurement of optic nerve sheath diameter to detect findings of increased intracranial pressure in adult head injury patients. Ann Emerg Med 2007;49(4):508-514. 
19. Geeraerts T, Newcombe VF, Coles JP, Abate MG, Perkes IE, Hutchinson PJ, Outtrim JG, Chatfield DA, Menon DK. Use of T2-weighted magnetic resonance imaging of the optic nerve sheath to detect raised intracranial pressure. Crit Care 2008;12(5):R114.

20. Foster T, Tayal V, Saunders T, et al. Emergency ultrasound optic nerve sheath measurement to detect increased intracranial pressure in head injury patients: preliminary study of interobserver variability in normal human subjects. Ultrasound Med Biol 2003;29(Suppl.5):S124.

21. Hansen HC, Helmke H. Validation of the optic nerve sheath response to changing cerebrospinal fluid pressure: ultrasound findings during intrathecal infusion tests. $\mathbf{J}$ Neurosurg 1997;87(1):34-40.

22. Bartel E. Color-coded duplex ultrasonography of the cerebral vessels. Atlas and manual. Stuttgart: Schattauer 1999:33.

23. Helmke K, Hansen HC. Fundamentals of transorbital sonographic evaluation of optic nerve sheath expansion under intracranial hypertension. I. Experimental study. Pediatr Radiol 1996;26(10):701-705.

24. Sutherland AI, Morris DS, Owen CG, Bron AJ, Roach RC. Optic nerve sheath diameter, intracranial pressure and acute mountain sickness on Mount Everest: a longitudinal cohort study. Br J Sports Med 2008;42(3):183-188.

25. Killer HE, Jaggi GP, Flammer J, Miller NR, Huber AR, Mironov A. Cerebrospinal fluid dynamics between the intracranial and the subarachnoid space of the optic nerve. Is it always bidirectional? Brain 2007;130(2):514-520.

26. Školoudík D., Škoda O, Bar M, Václavík D, Brozman M. Neurosonologie. Prague: Galen 2003. 


\section{Tables}

Table 1. Inclusion and exclusion criteria

\begin{tabular}{|l|l|}
\hline Inclusion criteria & $\begin{array}{l}\text { An acute stroke } \\
\text { The admission to the hospital within } 6 \text { hours after stroke onset }\end{array}$ \\
\cline { 2 - 2 } & A brain CT examination within 6 hours after stroke onset \\
\cline { 2 - 2 } & A TCCS examination within 6 hours after stroke onset \\
\hline Exclusion criteria & Signed informed consent \\
\hline & $\begin{array}{l}\text { Pathological findings on brain CT scan excluding acute intracerebral } \\
\text { hemorrhage or signs of acute ischemia }\end{array}$ \\
\hline & Insufficient temporal bone window \\
\hline
\end{tabular}

CT - computed tomography, TCCS - transcranial color-coded sonography 
Table 2. Demographic and clinical data in study subgroups

\begin{tabular}{|c|c|c|c|}
\hline & $\begin{array}{l}\text { Acute ICH } \\
\text { (31 subjects) }\end{array}$ & $\begin{array}{c}\text { Acute ischemic } \\
\text { stroke (15 subjects) }\end{array}$ & $\begin{array}{l}\text { Healthy volunteers } \\
\text { (16 subjects) }\end{array}$ \\
\hline Age (mean \pm SD; years) & $67.3 \pm 15.5$ & $67.7 \pm 12.5$ & $68.6 \pm 10.6$ \\
\hline Male gender (\%) & $16(52.0 \%)$ & $9(60.0 \%)$ & $9(56.0 \%)$ \\
\hline $\begin{array}{l}\text { Time stroke onset to ONS } \\
(\text { mean } \pm \text { SD; min) }\end{array}$ & $205.6 \pm 80.4$ & $214.8 \pm 70.3$ & - \\
\hline $\begin{array}{l}\text { NIHSS score at admission } \\
\text { (median, IQR) }\end{array}$ & $12.0,8.0-15.5$ & $10.0,7.0-14.5$ & - \\
\hline Arterial hypertension (\%) & $23(74.2 \%)$ & $11(73.3 \%)$ & $0(0.0 \%)$ \\
\hline Diabetes mellitus (\%) & $7(22.6 \%)$ & $5(33.3 \%)$ & $0(0.0 \%)$ \\
\hline Hyperlipidemia (\%) & $7(22.6 \%)$ & $6(40.0 \%)$ & $0(0.0 \%)$ \\
\hline Cigarette smoking (\%) & $9(29.0 \%)$ & $5(33.3 \%)$ & $4(25.0 \%)$ \\
\hline
\end{tabular}

ICH - intracerebral hemorrhage, IQR - interquartile range, NIHSS - National Institute of Health Stroke Scale, ONS - optic nerve sonography, SD - standard deviation 
Table 3. Diameters and relative enlargement of the optic nerve sheath in study subgroups

\begin{tabular}{|l|c|c|c|}
\hline & Acute ICH & Acute ischemic & Healthy \\
& & stroke & volunteers \\
\hline ONSD at 3.0 mm (mean, & $5.48,4.8$, & $3.42,3.3$, & $3.41,3.3$, \\
\hline median, IQR; mm) & $3.7-7.1 *$ & $3.0-3.7$ & $3.0-3.7$ \\
\hline ONSD at 12.0 mm (mean, & $3.31,3.3$, & $3.42,3.3$, & $3.37,3.3$, \\
\hline median, IQR; mm) & $3.0-3.6$ & $3.0-4.0$ & $3.1-3.7$ \\
\hline Enlargement in \% (mean, & $66.8,46.5$, & $0.13,0.0$, & $0.78,0.0$, \\
\hline median, IQR) & $7.0-115.9 *$ & $0.0-0.0$ & $-0.38-0.78$ \\
\hline Enlargement in mm & $2.17,1.5$, & $0.0,0.0$, & $0.04,0.0$ \\
\hline (mean, median, IQR) & $0.2-3.7 *$ & $0.0-0.0$ & $-0.03-0.1$ \\
\hline * p < 0.0083, ICH - intracerebral hemorrhage, IQR - interquartile range, ONSD - optic nerve
\end{tabular}


Table 4. Differences of optic nerve sheath diameters at $3 \mathrm{~mm}$ between the right and side in particular patients.

\section{Patient \# Optic nerve sheath diameter (mm)}

\begin{tabular}{lccc}
\hline & Right side & Left side & Difference \\
& & & \\
& & & \\
& & & \\
$\mathbf{1}$ & $3.9 \mathrm{~S}$ & 3.9 & 0.0 \\
$\mathbf{2}$ & $6.0 \mathrm{~S}$ & 5.8 & 0.2 \\
$\mathbf{3}$ & 3.4 & $3.3 \mathrm{~S}$ & 0.1 \\
$\mathbf{4}$ & 5.0 & $4.8 \mathrm{~S}$ & 0.2 \\
$\mathbf{5}$ & $6.0 \mathrm{~S}$ & 6.4 & 0.4 \\
$\mathbf{6}$ & $7.2 \mathrm{~S}$ & $8.0 \mathrm{~S}$ & 0.8 \\
$\mathbf{7}$ & 3.4 & $3.5 \mathrm{~S}$ & 0.1 \\
$\mathbf{8}$ & $3.6 \mathrm{~S}$ & 3.6 & 0.0 \\
$\mathbf{9}$ & $3.8 \mathrm{~S}$ & 3.8 & 0.0 \\
$\mathbf{1 0}$ & 7.1 & $6.7 \mathrm{~S}$ & 0.4 \\
$\mathbf{1 1}$ & 7.1 & $6.6 \mathrm{~S}$ & 0.5 \\
$\mathbf{1 2}$ & 3.4 & $3.5 \mathrm{~S}$ & 0.1 \\
$\mathbf{1 3}$ & 8.3 & $8.8 \mathrm{~S}$ & 0.5 \\
$\mathbf{1 4}$ & $3.0 \mathrm{~S}$ & 2.8 & 0.2 \\
$\mathbf{1 5}$ & $7.2 \mathrm{~S}$ & 7.8 & 0.6 \\
$\mathbf{1 6}$ & 6.6 & $6.0 \mathrm{~S}$ & 0.6 \\
$\mathbf{1 7}$ & 6.5 & $6.0 \mathrm{~S}$ & 0.5 \\
$\mathbf{1 8}$ & $8.5 \mathrm{~S}$ & 7.7 & 0.8 \\
\hline $\mathbf{1 9}$ & $8.2 \mathrm{~S}$ & 8.4 & 0.2 \\
$\mathbf{2 0}$ & $4.4 \mathrm{~S}$ & 4.2 & 0.2 \\
$\mathbf{2 1}$ & 3.9 & $3.8 \mathrm{~S}$ & 0.1 \\
$\mathbf{2 2}$ & 3.9 & $3.9 \mathrm{~S}$ & 0.0 \\
$\mathbf{2 3}$ & 3.4 & $3.3 \mathrm{~S}$ & 0.1 \\
$\mathbf{2 4}$ & 5.9 & $5.8 \mathrm{~S}$ & 0.1 \\
$\mathbf{2 5}$ & $4.8 \mathrm{~S}$ & 4.8 & 0.0 \\
$\mathbf{2 6}$ & $7.3 \mathrm{~S}$ & 7.9 & 0.6 \\
$\mathbf{2 7}$ & 4.5 & $4.5 \mathrm{~S}$ & 0.0 \\
$\mathbf{2 8}$ & $7.9 \mathrm{~S}$ & 8.5 & 0.6 \\
$\mathbf{2 9}$ & 3.3 & $3.5 \mathrm{~S}$ & 0.2 \\
$\mathbf{3 0}$ & 3.5 & 3.3 & 0.2 \\
$\mathbf{3 1}$ & $4.6 \mathrm{~S}$ & 4.8 & \\
\hline $\mathrm{S}-$ side of the intracerebral hemorrhage & & \\
\hline & & & \\
\hline
\end{tabular}


Table 5. Sensitivity, specificity, positive and negative predictive values, accuracy and

Cohen's $\kappa$ correlation coefficient for different sonographic cut-point values of optic nerve sheath enlargement to predict intracerebral hemorrhage volume $>2.5 \mathrm{~cm}^{3}$ and midline shift $\geq$ $2.0 \mathrm{~mm}$ in patients with acute intracerebral hemorrhage

\begin{tabular}{|c|c|c|c|c|}
\hline & & ONSD > $5 \mathrm{~mm}$ & $\begin{array}{c}\text { RR }>7 \% \\
\left(\mathrm{RD}>0.22 \mathrm{~mm}^{\ddagger}\right)\end{array}$ & $\begin{array}{c}\text { RR }>21 \%{ }^{\dagger} \\
\left(\mathrm{RD}>0.66 \mathrm{~mm}^{¥}\right)\end{array}$ \\
\hline \multirow{7}{*}{$\begin{array}{l}\text { Intracerebral } \\
\text { hemorrhage }\end{array}$} & $\begin{array}{l}\text { Sensitivity } \\
(95 \% \text { CI })\end{array}$ & $\begin{array}{c}0.708 \\
(0.620-0.708)\end{array}$ & $\begin{array}{c}0.875 \\
(0.676-0.973)\end{array}$ & $\begin{array}{c}0.875 \\
(0.676-0.973)\end{array}$ \\
\hline & $\begin{array}{l}\text { Specificity } \\
(95 \% \text { CI) }\end{array}$ & $\begin{array}{c}1.000 \\
(0.697-1.000)\end{array}$ & $\begin{array}{c}0.714 \\
(0.290-0.963\end{array}$ & $\begin{array}{c}1.000 \\
(0.652-1.000)\end{array}$ \\
\hline & $\begin{array}{l}\text { PPV } \\
(95 \% \mathrm{CI})\end{array}$ & $\begin{array}{c}1.000 \\
(0.875-1.000)\end{array}$ & $\begin{array}{c}0.913 \\
(0.720-0.989)\end{array}$ & $\begin{array}{c}1.000 \\
(0.867-1.000)\end{array}$ \\
\hline & $\begin{array}{l}\text { NPV } \\
(95 \% \mathrm{CI})\end{array}$ & $\begin{array}{c}0.500 \\
(0.348-0.652)\end{array}$ & $\begin{array}{c}0.625 \\
(0.245-0.915)\end{array}$ & $\begin{array}{c}0.700 \\
(0.348-0.933)\end{array}$ \\
\hline & $\begin{array}{l}\text { Accuracy } \\
(95 \% \text { CI) }\end{array}$ & $\begin{array}{c}0.774 \\
(0.627-0.921)\end{array}$ & $\begin{array}{c}0.839 \\
(0.663-0.946)\end{array}$ & $\begin{array}{c}0.903 \\
(0.743-0.980)\end{array}$ \\
\hline & $\begin{array}{l}\text { Cohen's } \kappa \\
(95 \% \mathrm{CI})\end{array}$ & $\begin{array}{c}0.523 \\
(0.251-0.795)\end{array}$ & $\begin{array}{c}0.561 \\
(0.219-0.902)\end{array}$ & $\begin{array}{c}0.760 \\
(0.509-1.000)\end{array}$ \\
\hline & $\mathrm{AC} 1$ & 0.591 & 0.745 & 0.839 \\
\hline \multirow{7}{*}{$\begin{array}{l}\text { Midline shift } \\
\geq 2.0 \mathrm{~mm}\end{array}$} & $\begin{array}{l}\text { Sensitivity } \\
(95 \% \text { CI })\end{array}$ & $\begin{array}{c}0.800 \\
(0.622-0.913)\end{array}$ & $\begin{array}{c}0.933 \\
(0.776-0.988)\end{array}$ & $\begin{array}{c}0.933 \\
(0.768-0.988)\end{array}$ \\
\hline & $\begin{array}{l}\text { Specificity } \\
(95 \% \text { CI })\end{array}$ & $\begin{array}{c}0.750 \\
(0.583-0.856)\end{array}$ & $\begin{array}{c}0.438 \\
(0.290-0.489)\end{array}$ & $\begin{array}{c}0.688 \\
(0.533-0.738)\end{array}$ \\
\hline & $\begin{array}{l}\text { PPV } \\
(95 \% \mathrm{CI})\end{array}$ & $\begin{array}{c}0.750 \\
(0.583-0.856)\end{array}$ & $\begin{array}{c}0.609 \\
(0.506-0.644)\end{array}$ & $\begin{array}{c}0.737 \\
(0.606-0.780)\end{array}$ \\
\hline & $\begin{array}{l}\text { NPV } \\
(95 \% \mathrm{CI})\end{array}$ & $\begin{array}{c}0.800 \\
(0.622-0.913)\end{array}$ & $\begin{array}{c}0.875 \\
(0.579-0.977)\end{array}$ & $\begin{array}{c}0.917 \\
(0.710-0.985)\end{array}$ \\
\hline & $\begin{array}{l}\text { Accuracy } \\
(95 \% \text { CI) }\end{array}$ & $\begin{array}{c}0.774 \\
(0.627-0.921)\end{array}$ & $\begin{array}{c}0.677 \\
(0.513-0.842)\end{array}$ & $\begin{array}{c}0.806 \\
(0.667-0.946)\end{array}$ \\
\hline & $\begin{array}{l}\text { Cohen's א } \\
(95 \% \text { CI })\end{array}$ & $\begin{array}{c}0.549 \\
(0.399-0.699)\end{array}$ & $\begin{array}{c}0.365 \\
(0.085-0.645)\end{array}$ & $\begin{array}{c}0.616 \\
(0.345-0.883)\end{array}$ \\
\hline & $\mathrm{AC} 1$ & 0.548 & 0.386 & 0.616 \\
\hline
\end{tabular}

$\S_{-9} 5^{\text {th }}$ percentile of ONSD relative enlargement ratio in healthy volunteers, ${ }^{\dagger}-$ ONSD

relative enlargement ratio three times over the $95^{\text {th }}$ percentile of in healthy volunteers, ${ }^{\ddagger}-95^{\text {th }}$ percentile of ONSD relative enlargement in healthy volunteers, ${ }^{\ddagger}-$ ONSD relative enlargement ratio three times over the $95^{\text {th }}$ percentile of ONSD relative enlargement in healthy volunteers, AC1 - AC1 coefficient, $\mathrm{CI}$ - confidence interval, ONSD - optic nerve 
sheath diameter, RD - relative difference in the ONSD in the depth $3.0 \mathrm{~mm}$ and in the depth $12.0 \mathrm{~mm}$ behind the globe, $\mathrm{RR}$ - relative ratio of the ONSD in the depth $3.0 \mathrm{~mm}$ and in the depth $12.0 \mathrm{~mm}$ behind the globe 
Figures

Figure 1: Normal finding of the optic nerve without enlargement of the optic nerve sheath diameter

Figure 2: Enlargement of the optic nerve sheath diameter in patient with acute intracerebral hemorrhage 
H1 Gn 14 $232 \mathrm{~dB} / \mathrm{C} 4$
$\mathrm{C} / 1 / 4$ 
Map 1 $170 \mathrm{~dB} / \mathrm{C} 4$ Persist Off 2D Opt:FSCT Fr Rate:Surv SonoCT $B$ $\mathrm{XRes}^{\mathrm{TM}}$

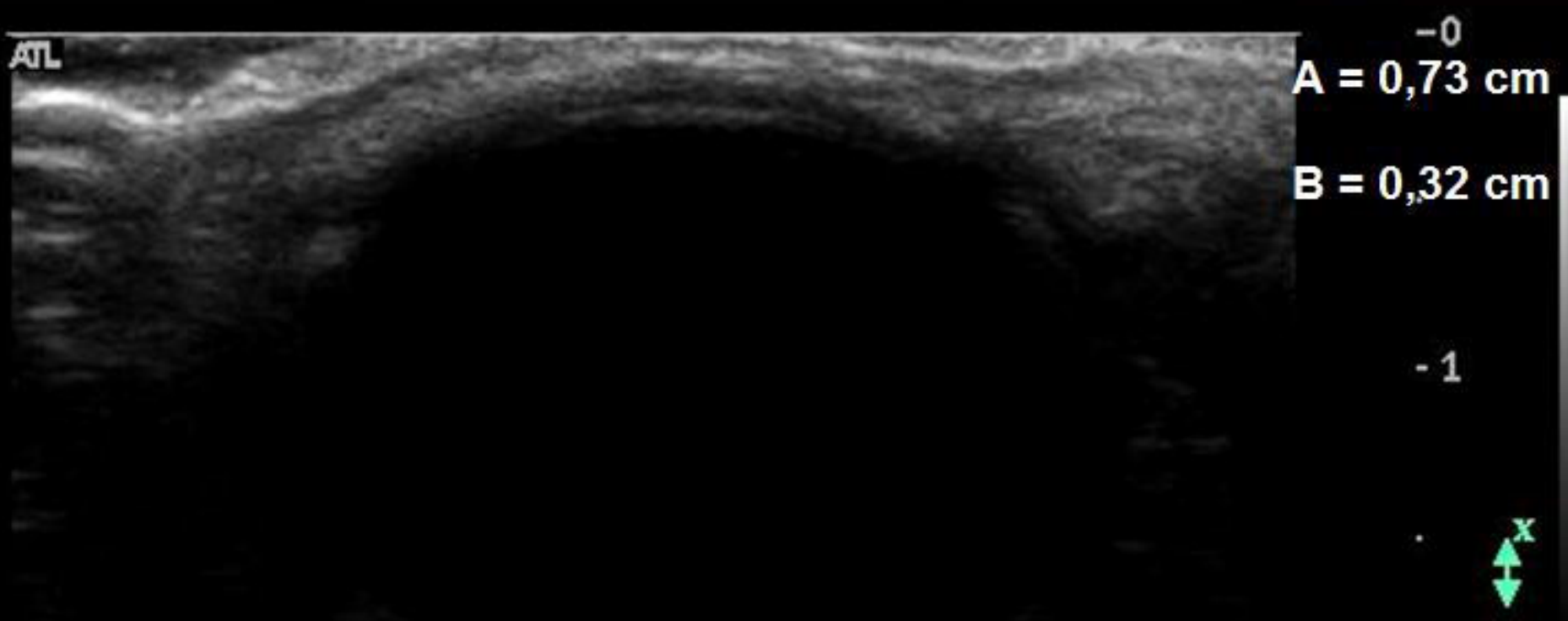

$-2$

A

B 